\title{
Comprehensive Benefit Analysis of Direct Expansion Ground Source Heat Pump System
}

\author{
Yuefen Gao, Yingxin Peng, Juanjuan Liu \\ School of Energy, Power \& Mechanical Engineering, North China Electric Power University, Baoding, China \\ Email: gaoyuefen@gmail.com
}

Received February 28, 2013; revised March 30, 2013; accepted April 13, 2013

Copyright (C) 2013 Yuefen Gao et al. This is an open access article distributed under the Creative Commons Attribution License, which permits unrestricted use, distribution, and reproduction in any medium, provided the original work is properly cited.

\begin{abstract}
Direct Expansion Ground Source Heat Pump (DXGSHP) system directly extracts heat or cold energy from ground by consuming electricity to provide for space conditioning. Compared with the currently widely-used secondary loop Ground Couple Heat Pump (GCHP) system, it has higher energy efficiency, lower operating costs, and less environmental impact. A case study is carried out in this paper. The subject is a residential building located in Beijing, China. It is assumed that the building adopts the DXGSHP system and the GCHP system respectively. Annual loads and energy consumption are simulated and computed. Then the initial cost, operating cost and $\mathrm{CO}_{2}$ emission are calculated. The economic benefit is analyzed with the Payback Time method and the Dynamic Annual Cost Value method. The environmental benefit is discussed mainly by comparing the $\mathrm{CO}_{2}$ emission savings. The results show that the DXGSHP system has higher initial costs, but lower operating costs, and less greenhouse gas emissions. The DXGSHP system has better comprehensive benefits than the GCHP system.
\end{abstract}

Keywords: Direct Expansion Ground Source Heat Pump; Economic Benefit; Environmental Benefit

\section{Introduction}

Ground Source Heat Pump (GSHP) system is a central heating and/or cooling system that pumps heat to or from the ground. It uses the earth (including soil, underground water) as a heat source in the winter or a heat sink in the summer. GSHP system has been widely used in the world for in excess of 30 years [1-4]. The GSHP exchanges heat with the ground, and maintain a high level of performance even in extreme climates for space conditioning. This results in more efficient use of energy.

Currently, most installed GSHP system is secondary loop Ground Coupled Heat Pump (GCHP) system. GCHP system employs the secondary loops buried underground. The loops are made of high-density polyethylene pipes and contain a mixture of water and antifreeze. The fluids exchange (extract or release) heat with the ground and circulate back to the heat exchanger where the fluids exchange heat with the refrigerant. So the refrigerant exchanges heat with the ground through the intermediate fluid loop. Esen et al. reported the experimental results that the average cooling performance coefficients $\left(\mathrm{COP}_{\text {sys }}\right)$ of the GCHP system for horizontal ground heat exchanger in the different trenches, at 1 and $2 \mathrm{~m}$ depths were obtained to be 3.85 and 4.26 , respec- tively, while the $\mathrm{COP}_{\text {sys }}$ of the Air Source Heat Pump (ASHP) system was determined to be 3.17 [5]. Some earlier studies concluded that GCHP systems were more viable than ASHP systems [6-8].

High efficiency to some extent means low $\mathrm{CO}_{2}$ emissions. Genchi et al. concluded that the regional heating and cooling system using a GCHP is a viable option for reducing $\mathrm{CO}_{2}$ emissions based on life-cycle $\mathrm{CO}_{2}$ emissions [9].

Recently, the merits of GSHP system have attracted great interest in research field and practical engineering applications in China [10-12]. China possesses vast land area, and the ground temperature varies between $7^{\circ} \mathrm{C}$ and $23^{\circ} \mathrm{C}$ from North China to South China. The moderate ground temperature provides an optimal condition to space heating and cooling. Potential heat stored underground can be pumped out to provide higher temperature air or water for a building in the winter. In the summer heat absorbed from the building can be transferred and discarded into the ground.

If the refrigerant pipe is buried underground and exchanges heat directly with the ground, the system becomes Direct Expansion Ground Source Heat Pump (DXGSHP) system. In this system, the pipe buried un- 
derground circulates the refrigerant and acts as the evaporator or condenser. The intermediate medium loop is eliminated. So is the circulating pump. Heat loss is reduced by exchanging heat directly between the refrigerant and the ground. Thereby the thermal efficiency of the DXGSHP system is improved, and then the length of the buried pipe or pipe laying depth are reduced.

However, as the DXGSHP system uses costly copper pipe and charges more refrigerant, this weakens its inherent advantages to some extent and is also one of the reasons hindering its promotion. This paper evaluates the DXGSHP system from the aspects of economic and environmental benefits based on the comparison between the GCHP and the DXGSHP systems.

\section{Description of DXGSHP System}

DXGSHP system consists of heat pump units and terminal equipment. Among them, the main components are similar to the common refrigerating and heat pump units, except for the outdoor heat exchanger. The outdoor heat exchanger in the DXGSHP system is buried in the earth. Refrigerant exchanges heat with ground through the buried pipe as shown in Figure 1.

DXGCHP system uses electricity to drive the compressor and extracts heat or cold energy from ground to provide for space conditioning. Because the system not only has no pumps but also has few heat losses, it can obtain high COP. The practical test results demonstrate that COP of DXGSHP system is 6.03 in summer and 6.24 in winter [13]. Generally, COP of the GCHP system is 4.5 - 5.0 in summer and 3.5 in winter. The DXGSHP system obviously has higher efficiency.

High efficiency enables the system to reduce energy consumption and operating cost. When energy consumed has the effect of environment pollution, high efficiency means pollution abatement to the environment. At the same time, high efficiency can also decreases the equipment and system size. Thus improving efficiency of the

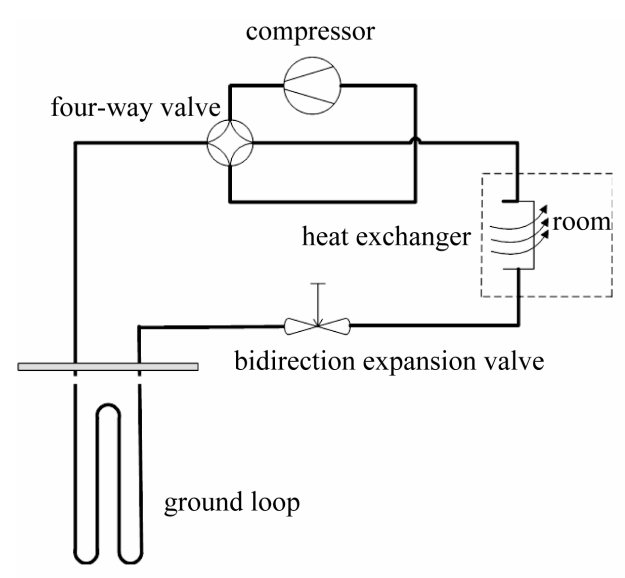

Figure 1. Schematic of a DXGCHP system. system is the main target of system optimization.

In the DXGSHP system, the pipe circulating refrigerant directly exchanges heat with the earth. Compared with the GCHP system, the DXGSHP system has higher heat transfer temperature differences and smaller thermal resistance, so it owns much more heat exchange capacity per unit length. Generally in the GCHP system, the heat exchange capacity per unit length of the buried pipe is 35 $\mathrm{W} / \mathrm{m}$ [14], while in the DXGSHP system, it reaches 50 $\mathrm{W} / \mathrm{m}$, which is 1.4 times of the former. Therefore, the buried pipe length, the borehole depth and the occupied land space of the DXGSHP system are less than those of the GCHP system. Accordingly, the initial costs of the DXGSHP system are nearly equal to or even less than those of the GCHP system.

\section{Introduction of Scenarios}

This paper will evaluate the DXGSHP system from the aspects of economic and environmental benefits by comparing it with the GCHP system.

\subsection{Description of Building and Its Environs}

The residential building being studied is about 500 square meters of floor area. This building is located in Beijing. The walls are made of aerated concrete, and are insulated with benzene slab. All windows are double glazing with inert gas sandwiches. The pitched roof consists of benzene slab insulating layer, damp-proof course and surface course.

Beijing is situated in North China. It has a humid continental climate (DWb) according to Koppen climate classification. Figure 2 shows the hourly air temperature in a typical meteorological year of Beijing. Based on the data above, the annual dynamic loads are simulated with DeST (a simulation tool developed by Tsinghua University). Referring to the meteorological parameters of Beijing and usual practice in China, the cooling season is assumed from 1 June through 30 August (total 90 days) each year, while the heating season is from 1 November to 20 March next year (total 140 days). The annual loads are depicted in Figure 3.

\subsection{Details of Scenarios}

The DXGSHP system uses 4 sets of scroll heat pump units with rated cooling capacity of $12 \mathrm{~kW}$ and rated heating capacity of $12.6 \mathrm{~kW}$ for each heat pump. Each unit needs 4 boreholes, spaced at $5 \mathrm{~m}$ in a $4 \times 4$ grid, with excavation area of $400 \mathrm{~m}^{2}$. Each borehole is $40 \mathrm{~m}$ deep and $100 \mathrm{~mm}$ in diameter. A single U loop is placed in each borehole.

The GCHP system employs one set of scroll heat pump unit with rated cooling capacity of $76 \mathrm{~kW} .16$ boreholes are drilled in a $4 \times 4$ grid, with a spacing of 5 


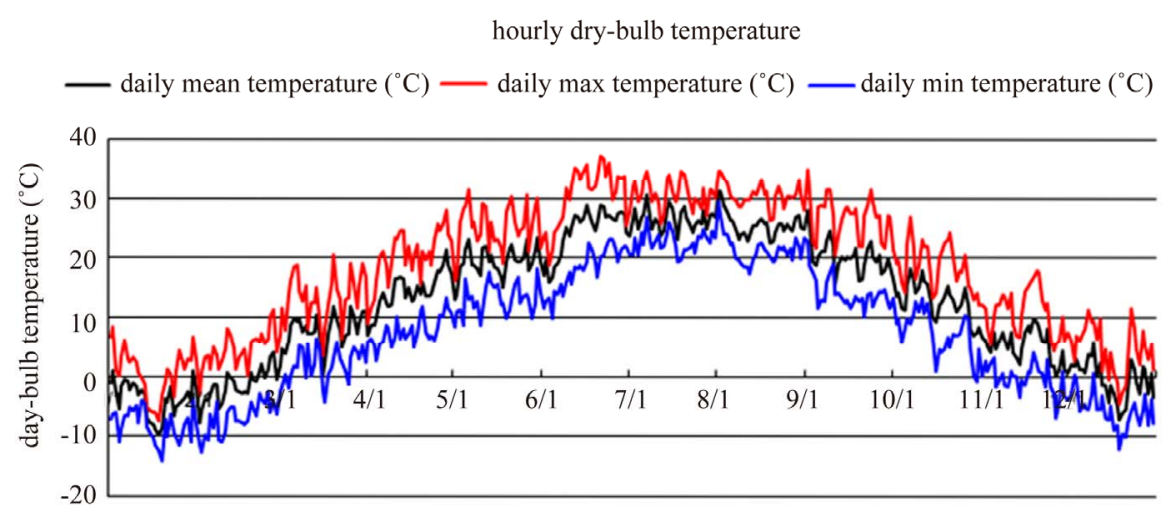

Figure 2. Hourly air temperature in a typical meteorological year of Beijing.

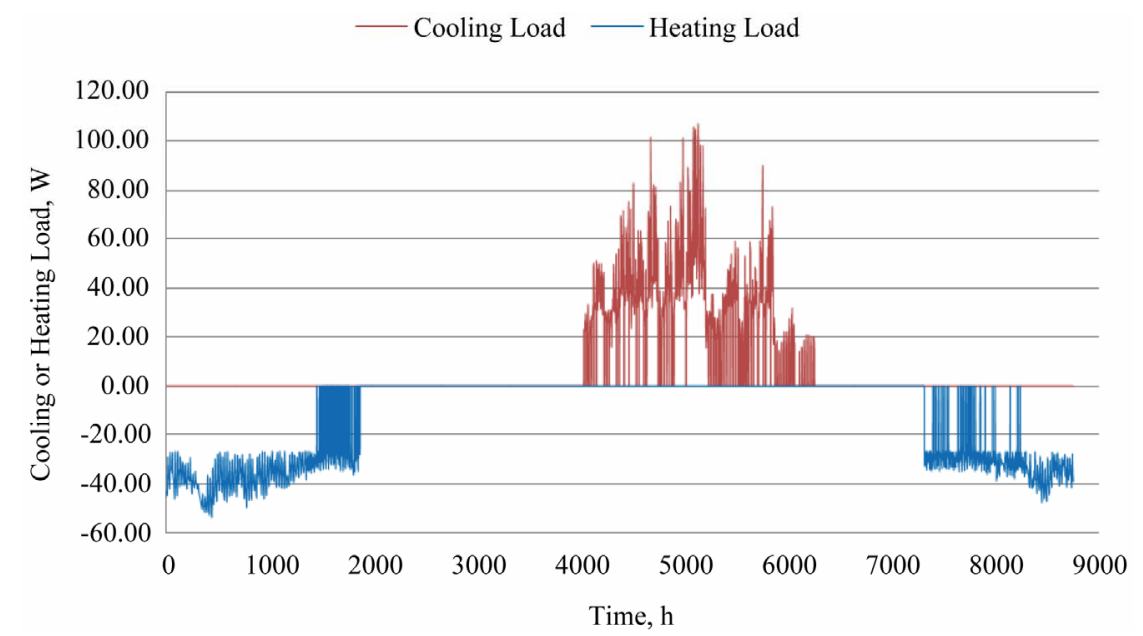

Figure 3. Annual cooling and heating load of the building.

$\mathrm{m}$ and excavation area of $400 \mathrm{~m}^{2}$ as well. Each borehole is $100 \mathrm{~m}$ deep and $110 \mathrm{~mm}$ in diameter. Each borehole contains a single U loop.

The details of the equipment in each scenario are shown in Table 1.

\subsection{Initial Cost}

Initial costs include the costs of the heat pump, terminal equipment, distribution pipeline, and drilling borehole as well. It is noted that the ground loop and borehole drilling costs much. It accounts for about $1 / 3$ to $1 / 2$ of the total initial investments. In the DXGSHP system, the costly copper tubing costs much more than the same length plastic tubing. Nevertheless, the high efficiency allows the system using shorter and smaller closed loops and boreholes, which potentially contributes to reducing initial costs. The initial costs of the two scenarios list in Table 2.

\subsection{Energy Consumption and Operating Cost of Each Scenario}

Both the DXGSHP system and the GCHP system are powered by electricity. The average price of electricity is 1.0 CNY per kWh (0.041 \$/MJ). Assuming the system runs totally 90 days yearly in the cooling season and 140 days yearly in the heating season.

Under these conditions, the annual electricity consumed and operating costs of the two systems are shown in Table 3.

\section{Analysis of Economic Benefit}

\subsection{Payback Time of Initial Investment}

The economic benefit of the systems can be evaluated with Payback Time (PT) method. Generally, this method includes static payback time (SPT) and dynamic payback time (DPT).

Static investment payback time is calculated by:

$$
N=I / E
$$

Dynamic investment payback time is calculated by:

$$
N^{\prime}=\frac{\lg E-\lg (E-I \times i)}{\lg (1+i)}
$$

where $N$ and $N$ denote the static and dynamic payback 
Table 1. Specifics of equipment of the DXGSHP and GCHP system.

\begin{tabular}{lll}
\hline & DXGSHP system & GCHP system \\
\hline \multirow{2}{*}{ Model } & Scroll heat pump & $\begin{array}{l}\text { Scroll heat pump: } \\
\text { SM(D)-20Q(R) }\end{array}$ \\
& 4 & 1 \\
Amount & Cooling: $12 \times 4$ & Cooling: $76 \times 1$ \\
Rated capacity $(\mathrm{kW})$ & Heating: $12.5 \times 4$ & Heating: $64 \times 1$ \\
Power input $(\mathrm{kW}$, & Cooling: $1.99 \times 4$ & Cooling: $17.2 \times 1$ \\
including pump power) & Heating: $2.0 \times 4$ & Heating: $20.2 \times 1$ \\
COP & Cooling: 6.03 & Cooling: 4.42 \\
& Heating: 6.25 & Heating: 3.17 \\
\hline
\end{tabular}

Table 2. Initial cost of the DXGSHP and GCHP system.

\begin{tabular}{ccc}
\hline & DXGSHP system & GCHP system \\
\hline $\begin{array}{c}\text { Host equipment } \\
\left(\times 10^{3} \mathrm{CNY}^{\mathrm{a}}\left(\times 10^{3} \$\right)\right)\end{array}$ & $151.0(22.1)^{\mathrm{b}}$ & $42.0(6.2)^{\mathrm{b}}$ \\
Buried pipe and drilling cost & $100.0(14.7)^{\mathrm{b}}$ & $110.0(16.2)^{\mathrm{b}}$ \\
$\begin{array}{c}\left(\times 10^{3} \mathrm{CNY}^{\mathrm{a}}\left(\times 10^{3} \$\right)\right) \\
\text { Auxiliary equipment }\end{array}$ & - & $151.0(2.2)^{\mathrm{b}}$ \\
$\left(\times 10^{3} \mathrm{CNY}^{\mathrm{a}}\left(\times 10^{3} \$\right)\right)$ & $50.0(7.4)^{\mathrm{b}}$ & $90.0(13.2)^{\mathrm{b}}$ \\
$\begin{array}{c}\text { Terminal equipment } \\
\left(\times 10^{3} \mathrm{CNY}^{\mathrm{a}}\left(\times 10^{3} \$\right)\right)\end{array}$ & $301.0(44.2)^{\mathrm{b}}$ & $257.0(37.8)^{\mathrm{b}}$ \\
\hline Total initial cost & & \\
$\left(\times 10^{3} \mathrm{CNY}^{\mathrm{a}}\left(\times 10^{3} \$\right)\right)$ & & \\
\hline
\end{tabular}

${ }^{\mathrm{a}} \mathrm{CNY}$ denotes China Yuan, and the same in Table 3 and Table 4; ${ }^{\mathrm{b}}$ Numbers in brackets is in US dollars, and the same in Table $\mathbf{3}$ and Table 4.

Table 3. Yearly energy consumed and operating cost of the DXGSHP and GCHP system.

\begin{tabular}{ccccc}
\hline & \multicolumn{2}{c}{ DXGSHP system } & \multicolumn{2}{c}{ GCHP system } \\
\cline { 2 - 5 } & Cooling & Heating & Cooling & Heating \\
\hline $\begin{array}{c}\text { Energy consumed } \\
\text { (MWh) }\end{array}$ & 5.47 & 8.25 & 7.45 & 16.27 \\
$\begin{array}{c}\text { Annual operating cost } \\
\left(\times 10^{3} \text { CNY }^{\mathrm{a}}\left(\times 10^{3} \$\right)\right)\end{array}$ & 5.47 & 8.25 & 7.45 & 16.27 \\
Total operating & $(0.80)^{\mathrm{b}}$ & $(1.21)^{\mathrm{b}}$ & $(1.10)^{\mathrm{b}}$ & $(2.39)^{\mathrm{b}}$ \\
$\begin{array}{c}\text { cost yearly } \\
\left(\times 10^{3} \mathrm{CNY}^{\mathrm{a}}\left(\times 10^{3} \$\right)\right)\end{array}$ & \multicolumn{2}{c}{13.72} & \multicolumn{2}{c}{23.72} \\
\hline
\end{tabular}

time respectively; $I$ is the investment difference between the DXGSHP and GCHP system; $E$ is difference of the yearly operating cost between the two systems; $i$ is the interest rate, taken $5.76 \%$ ( 3 - 5 years) in this paper.

According to Equations (1) and (2), the static payback time is 4.4 years and the dynamic payback time is 5.2 years for the DXGSHP system over the GCHP system, based on the data in Tables 2 and $\mathbf{3}$. Thus, the DXGSHP system has higher initial investment, but lower operating cost than the GCHP system.

\subsection{Dynamic Annual Cost Value}

The Payback Time method can't reflect the time value of the initial investment. When the systems have different lifespan and maintenance cost, it is necessary to consider the time value of the investment. Normally, the concep- tion of Dynamic Annual Cost Value (DACV) is introduced to evaluate the value of the whole system in its lifespan. It is calculated by $[15,16]$ :

$$
Z=\frac{i(1+i)^{m}}{(1+i)^{m}-1} \times I+M
$$

where $Z$ represents the dynamic annual cost; $i$ is the interest rate, taken $8 \%$ (for $15-25$ years lifespan) in this project; $m$ is lifespan of the system, 25 years for both the DXGSHP and GCHP system; $I$ is the initial cost (see Table 2); $M$ means the annual operating cost and maintenance paid (see Table 3).

Table 4 shows the Dynamic Annual Cost Value of the two scenarios.

The results in Table 4 indicate that the DXGSHP system has better economic benefit than the GCHP system.

\section{Analysis of Environmental Benefit}

GSHP systems offer significant greenhouse gas (GHG) emission reductions potentially, particularly where they are used for both heating and cooling. High energy efficiency means lower energy consumption, and thereby less electricity required. In China, electricity is generated and supplied by thermal power plant. So electricity supply accompanies large quantities of greenhouse gas emissions, especially $\mathrm{CO}_{2}$ emissions. $\mathrm{CO}_{2}$ emissions intensity in China is $839 \mathrm{~kg} / \mathrm{MWh}$. The DXGSHP system has higher efficiency than the GCHP system, so the $\mathrm{CO}_{2}$ emission savings for the DXGSHP system over the GCHP system can be calculated by:

$$
E S=\left(E_{\mathrm{GCHP}}-E_{\mathrm{DXGSHP}}\right) \times E I
$$

where $E S$ is $\mathrm{CO}_{2}$ emission savings per year, kg; $E_{\mathrm{GCHP}}$ and $E_{\mathrm{DXGSHP}}$ are electricity consumed per year by the GCHP system and the DXGSHP system respectively, MWh; EI is $\mathrm{CO}_{2}$ emissions intensity of electricity, $\mathrm{kg} / \mathrm{MWh}$.

According to Equation (4) and the data in Table 3, the DXGSHP system can save $\mathrm{CO}_{2}$ emissions of $8390 \mathrm{~kg}$ annually relative to the GCHP system. $\mathrm{CO}_{2}$ emissions of the DXGSHP system reduce more than $40 \%$ relative to the GCHP system. The reduction of $\mathrm{CO}_{2}$ emissions is mainly attributed to high energy efficiency. Specifically,

Table 4. Dynamic annual cost value for DXGSHP and GCHP system.

\begin{tabular}{ccc}
\hline & DXGSHP system & GCHP system \\
\hline $\begin{array}{c}\text { Initial cost } \\
\left(\times 10^{3} \mathrm{CNY}^{\mathrm{a}}\left(\times 10^{3} \$\right)\right)\end{array}$ & $301.0(44.26)^{\mathrm{b}}$ & $257.0(37.79)^{\mathrm{b}}$ \\
$\begin{array}{c}\text { Operating cost } \\
\left(\times 10^{3} \mathrm{CNY}^{\mathrm{a}}\left(\times 10^{3} \$\right)\right)\end{array}$ & $13.72(2.01)^{\mathrm{b}}$ & $23.72(3.49)^{\mathrm{b}}$ \\
$\begin{array}{c}\text { Dynamic Annual Cost } \\
\left(\times 10^{3} \mathrm{CNY}^{\mathrm{a}}\left(\times 10^{3} \$\right)\right)\end{array}$ & $41.92(6.16)^{\mathrm{b}}$ & $47.80(7.03)^{\mathrm{b}}$ \\
\hline
\end{tabular}


the DXGSHP system has high efficiency units, eliminates the circulating pumps and reduces the heat losses, thus the energy consumption decreases and energy efficiency increases.

Simultaneously, unlike the open loop system, both the DXGSHP system and the GCHP system have no risk of aquifer depletion, water shortages, groundwater contamination, and subsidence of the soil, as they don't require to extract water from a well and to drain to the surface. As long as fluids used in the closed loops are biodegradable and non-toxic, both the systems have little influence on the vegetation adhere to the ground.

\section{Conclusions}

This paper investigates into the benefits of the DXGSHP system from the aspects of initial cost, operating cost and environmental impact through comparison with the GCHP system.

The DXGSHP system eliminates the secondary loop, the intermediate medium, and the circulating pump. It also decreases heat losses in the process of exchanging heat with the ground. Hence, the DXGSHP system possesses high energy efficiency. However, the refrigerant pipe made of costly copper instead of high density polyethylene increases the initial investment.

In terms of economic benefit, the DXGSHP system has higher initial cost, but lower operating cost due to its higher energy efficiency. The Payback Time of the DXGSHP system over the GCHP system is respectively 4.4 years of Static Payback Time and 5.2 years of Dynamic Payback Time. The Dynamic Annual Cost Value is lower than that of the GCHP system.

As for the environmental benefit, the DXGSHP system exploits the shallow renewable geothermal energy and has less greenhouse gas emissions. $\mathrm{CO}_{2}$ emissions of the DXGSHP system reduce $40 \%$ relative to the GCHP system. The reduction of $\mathrm{CO}_{2}$ emissions is mainly due to its high energy efficiency.

Further studies should focus on seeking measures to reduce initial costs and to enhance energy efficiency, and seeking low GHG emissions and non-toxic working fluids.

\section{Acknowledgements}

All authors are grateful to the financial support by the Fundamental Research Funds for the Central Universities (Project No: 11MG43).

\section{REFERENCES}

[1] J. R. Goulburn and J. Fearon, "Deep Ground Coil Evaporators for Heat Pumps,” Applied Energy, Vol. 4, No. 4, 1978, pp. 293-313. doi:10.1016/0306-2619(78)90028-4

[2] J. R. Goulburn and J. Fearon, "Domestic Heat Pump with
Deep Hole Ground Source Evaporator,” Applied Energy, Vol. 14, No. 2, 1983, pp. 99-113.

doi:10.1016/0306-2619(83)90012-0

[3] J. Y. Lee, "Current Status of Ground Source Heat Pumps in Korea," Renewable and Sustainable Energy Reviews, Vol. 13, No. 6-7, 2009, pp. 1560-1568. doi:10.1016/j.rser.2008.10.005

[4] B. Sanner, C. Karytsas, D. Mendrinos and I. Rybach, "Current Status of Ground Source Heat Pumps and underground Thermal Energy Storage in Europe," Geothermics, Vol. 32, No. 4-6, 2003, pp. 579-588. doi:10.1016/S0375-6505(03)00060-9

[5] E. Hikmet, M. Inalli and M. Esen, “A Techno-Economic Comparison of Ground-Coupled and Air-Coupled Heat Pump System for Space Cooling,” Building and Environment, Vol. 42, No. 5, 2007, pp. 1955-1965. doi:10.1016/j.buildenv.2006.04.007

[6] P. F. Healy and V. I. Ugursal, "Performance and Economic Feasibility of Ground Coupled Heat Pumps in Cold Climate,” International Journal of Energy Research, Vol. 21, No. 10, 1997, pp. 857-870. doi:10.1002/(SICI)1099-114X(199708)21:10<857::AIDER279>3.0.CO;2-1

[7] P. J. Petit and J. P. Meyer, “A Techno-Economic Analytical Comparison of the Performance of Air-Coupled and Horizontal-Ground Coupled Air Conditioners in South Africa,” International Journal of Energy Research, Vol. 21, No. 11, 1997, pp. 1011-1021.

doi:10.1002/(SICI)1099-114X(199709)21:11<1011::AID -ER307>3.0.CO;2-L

[8] P. J. Petit and J. P. Meyer, "Economic Potential of GroundCoupled Heat Pumps Compared to Air-Coupled Air Conditioners in South Africa,” Energy, Vol. 23, No. 2, 1998, pp. 137-143. doi:10.1016/S0360-5442(97)00057-1

[9] Y. Genchi, Y. Kikegawa and A. Inaba, " $\mathrm{CO}_{2}$ PaybackTime Assessment of a Regional-Scale Heating and Cooling System Using a Ground Coupled Heat-Pump in a High Energy-Consumption Area in Tokyo,” Applied Energy, Vol. 71, No. 3, 2002, pp. 147-160. doi:10.1016/S0306-2619(02)00010-7

[10] J. Liang, Q. C. Yang, L. C. Liu and X. Y. Li, "Modeling and Performance Evaluation of Shallow Ground Water Heat Pumps in Beijing Plain, China,” Energy and Buildings, Vol. 43, No. 11, 2011, pp. 3131-3138. doi:10.1016/j.enbuild.2011.08.007

[11] W. Yang, J. Zhou, W. Xu and G. Q. Zhang, "Current Status of Ground-Source Heat Pumps in China," Energy Policy, Vol. 38, No. 1, 2010, pp. 323-332. doi:10.1016/j.enpol.2009.09.021

[12] X. D. Zhang, Y. Q. Jiang and Y. Yao, "Improved Method and Case Study of Ground-Coupled Heat Pump System Design,” Energy Procedia, Vol. 16, 2012, pp. 849-855. doi:10.1016/j.egypro.2012.01.136

[13] Y. H. Guo, G. Q. Zhang, J. Zhou, J. S. Wu and W. Shen, "Design and Performance of a Direct Expansion GroundSource Heat Pump System,” Journal of Chongqing University, Vol. 34, No. S1, 2011, pp. 52-56.

[14] D. Banks, "An Introduction to Thermogeology: Ground Source Heating and Cooling,” Blackwell Publishing Ltd., 
Oxford, 2008. doi:10.1002/9781444302677

[15] Y. H. Guo, G. Q. Zhang, J. Zhou, J. S. Wu and W. Shen, "A Techno-Economic Comparison of a Direct Expansion Ground-Source and a Secondary Loop Ground-Coupled Heat Pump System for Cooling in a Residential Building," Applied Thermal Engineering, Vol. 35, 2012, pp.
29-39. doi:10.1016/j.applthermaleng.2011.09.032

[16] X. H. Shen, "The Economy Analysis of Ground-Source Heat Pump Technology in Chengdu Area,” Modern Business Trade Industry, No. 17, 2009, pp. 304-306. (in Chinese) 